\title{
Morphology and electronic structure of nanoscale powders of calcium hydroxyapatite
}

\author{
Nataly Kurgan ${ }^{1 *}$, Volodymyr Karbivskyy ${ }^{1}$ and Vasyl Kasyanenko ${ }^{2}$
}

\begin{abstract}
Atomic force microscopy, infrared spectroscopy and NMR studied morphological and physicochemical properties of calcium hydroxyapatite powders produced by changing the temperature parameters of synthesis. Features of morphology formation of calcium hydroxyapatite nanoparticles with an annealing temperature within $200^{\circ} \mathrm{C}$ to $1,100^{\circ} \mathrm{C}$ were determined. It is shown that the particle size of the apatite obtained that annealed $700^{\circ} \mathrm{C}$ is $40 \mathrm{~nm}$ corresponding to the particle size of apatite in native bone. The effect of dimension factor on structural parameters of calcium hydroxyapatite is manifested in a more local symmetry of the $\mathrm{PO}_{4}{ }^{3-}$ tetrahedra at nanodispersed calcium hydroxyapatite.
\end{abstract}

Keywords: Atomic force microscopy; Hydroxyapatite; Morphology; Electronic structure

PACS: 87.64.Dz; 87.64.kj; 87.80.Lg

\section{Background}

Bioactive materials based on calcium hydroxyapatite $\left(\mathrm{Ca}_{10}\left(\mathrm{PO}_{4}\right)_{3}(\mathrm{OH})_{2}, \mathrm{HAP}\right)$, the chemical composition and structure of which approaches the mineral component of bones, are widely used in medical practice over the past 20 years. All the time, the researches continue to work for improvement of these materials [1-4]. However, the prospect of their application may not be quite complete without clarifying the relationship of morphological, physical and chemical properties, and atomic architecture surfaces of these materials because biocompatibility is dependent not only on their chemical composition but also to a large extent on the morphology of the particles, which affect the interaction of mineral constituent of bones with the organic matrix. In view of the fact that such material should be included in the metabolism of the body and be replaced with a full bone tissue, it remains relevant to obtain nanodispersed calcium hydroxyapatite with parameters that match the parameters of particle maximum mineral component of bones [5-8]. This article presents the results of a study of morphological and physicochemical properties of calcium hydroxyapatite powders obtained at various temperature parameters of synthesis.

\footnotetext{
* Correspondence: nataly_kurgan@mail.ru

${ }^{1}$ G.V. Kurdymov Institute for Metal Physics of the NAS of Ukraine, blvd. Vernadsky, 36, Kiev 03680, Ukraine

Full list of author information is available at the end of the article
}

\section{Methods}

Preparation of calcium hydroxyapatite

For preparation of hydroxyapatite powder, calcium nitrate tetrahydrate and diammonium hydrogen phosphate (reagent grade) were used as calcium and phosphorus precursors, respectively. Both reagents were purchased from Merck, Darmstadt, Germany. Urea (R\&M Chemicals, Edmonton, UK) was used as gelling and ammonium donor agent. EDTA (Merck) was used as a chelating agent to prevent an immediate precipitate formation calcium ion in the course of gel formation. The reaction was conducted in a basic solution using ammonium solution (R\&M Chemicals) as a solvent. Ammonium solution was heated at $60^{\circ} \mathrm{C}$, and EDTA (182 g) was added while stirring until it dissolved. Into this, $200 \mathrm{~mL}$ of aqueous solution of $128 \mathrm{~g}$ calcium nitrate tetrahydrate was poured. Diammonium hydrogen phosphate (39.83 g) and urea $(45.20 \mathrm{~g})$ were subsequently added. The mixture was heated at $100^{\circ} \mathrm{C}$ for 3 to $4 \mathrm{~h}$. The obtained gel was dried at $150^{\circ} \mathrm{C}$ under ambient static air and subsequently subjected to an $200^{\circ} \mathrm{C}, 500^{\circ} \mathrm{C}, 700^{\circ} \mathrm{C}, 900^{\circ} \mathrm{C}, 1,000^{\circ} \mathrm{C}$, and $1,100^{\circ} \mathrm{C}$ calcination under flowing air for $1 \mathrm{~h}$. The powder was examined by X-ray diffraction techniques to determine the phases formed. It was observed that $\mathrm{Ca} / \mathrm{P}$ molar ratio is 1.667 . (c) 2015 Kurgan et al.; licensee Springer. This is an Open Access article distributed under the terms of the Creative Commons Attribution License (http://creativecommons.org/licenses/by/4.0), which permits unrestricted use, distribution, and reproduction in any medium, provided the original work is properly credited. 


\section{Morphology investigation}

Morphology of hydroxyapatite powder has been investigated by scanning probe microscope JSPM-4500/4610 (JEOL, Tokyo, Japan) using atomic force microscopy. Imaging parameters were as follows: image size $90.0 \times$ $90.0 \mathrm{~nm}$, image height $12.2 \mathrm{~nm}$, and exposure time at $83.33 \mu \mathrm{s}$. As the scanning probe made of cantilever with a diamond tip of the NSG-10-DLC. Operational vacuum was no worse than $10^{-7} \mathrm{~Pa}$.

\section{Infrared spectroscopy investigation}

IR spectra were obtained on double-beam spectrophotometer SPECORD M80 (Carl Zeiss, Jena, Germany). To provide the study, the samples were prepared by compressing into the mixed tablets of the compound and powdered $\mathrm{KBr}$. Tablets of pure $\mathrm{KBr}$ powder were also prepared to measure of the sample phonon transmission. Transmission spectra were recorded in the absorption range of the tetrahedral sublattice $\mathrm{PO}_{4}^{3-}$ with vibrational modes lying in the 4,000 to $400 \mathrm{~cm}^{-1}$ range.

In the region of slow electromagnetic waves, sharp $\mathrm{KBr}$ powder absorption begins; therefore, the measurement in the range $<400 \mathrm{~cm}^{-1}$ is not correct. The measurements were made at a constant level of signal/noise ratio in the whole measurement range. To optimize the recording of the spectra, an electromagnetic radiation attenuator was also installed in comparison channel, so that the absorption background level of $\mathrm{KBr}$ pellet approaches to $80 \%$. During the measurements, the sample chamber was additionally blown through with dry air for thorough drying of water vapor.

\section{NMR investigation}

NMR spectra were recorded on a spectrometer Avance 400 (Bruker, Ettlingen, Germany) at room temperature. NMR spectra were obtained from rotation of the sample under the magic angle (MAS NMR) at frequencies of 10 and $15 \mathrm{kHz}$, which eliminates the effects of anisotropy and dipole-dipole interaction, but does not exclude the quadrupole interaction of the second order.

\section{Results and discussion}

\section{Morphology of nanoscale powders}

It should be noted that the powders obtained by sol-gel method formation of apatite are similar with the formation of apatite in bone native mechanism: colloidal solutionamorphous condensate-crystal phase. Kinetic chain synthesis involves the transformation of sol in the gel, condensation precipitate, rinsed with water, and drying. Since the composition of the amorphous shell in particles cannot be determined, we can conclude only a disordered agglomeration of the molecules. Transition of amorphous condensate-crystal phase is observed in samples obtained at $200^{\circ} \mathrm{C}$. Simultaneous formation of amorphous particles

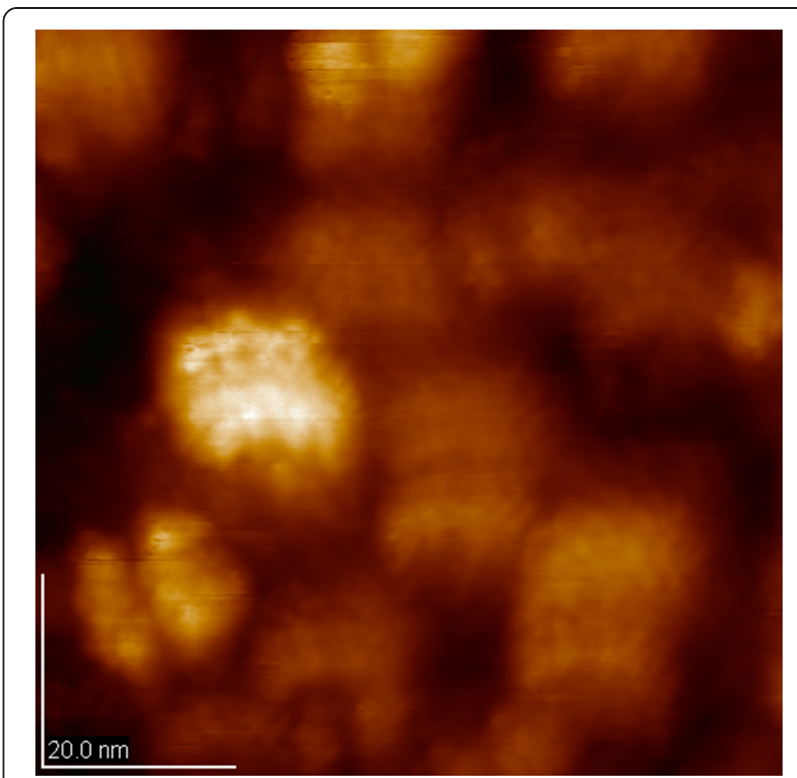

Figure 1 AFM image of HAP samples obtained at the temperature of $200^{\circ} \mathrm{C}$. Transition of amorphous condensate-crystal phase is observed in samples obtained at $200^{\circ} \mathrm{C}$. There are clusters of crystal phase size 10 to $15 \mathrm{~nm}$ in an amorphous matrix. Image size is $90.0 \times 90.0 \mathrm{~nm}$.

begins with the process of crystallization, i.e., begins with the formation of the long-range order within the amorphous phase. There are clusters of crystal phase size 10 to $15 \mathrm{~nm}$ in an amorphous matrix (Figure 1).

When the temperature reaches up to $500^{\circ} \mathrm{C}$, it shows an increase in the size of the crystal phase clusters. Aspiration systems reduce the surface energy leads to the

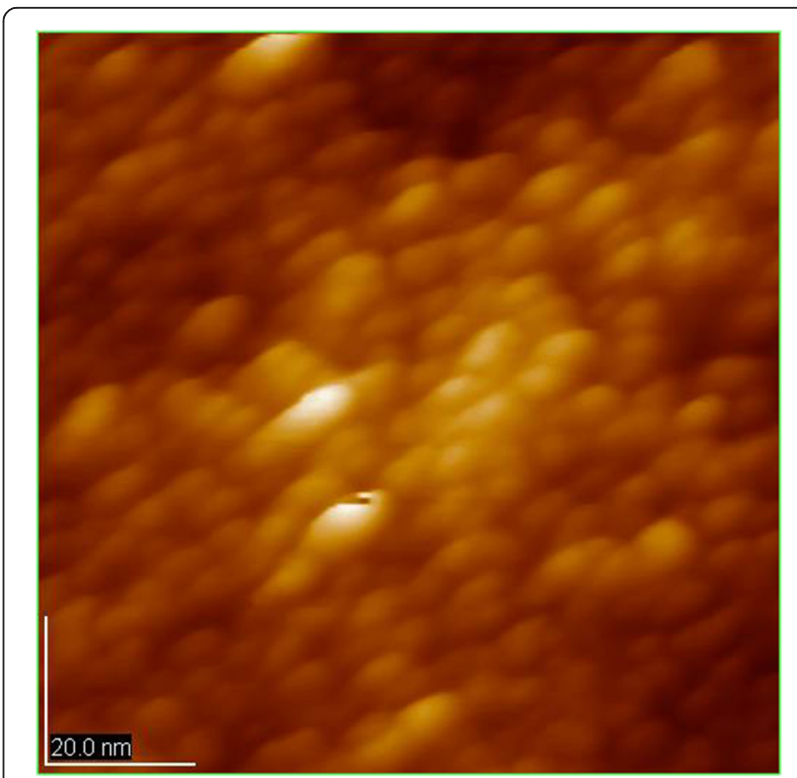

Figure 2 AFM image of HAP samples obtained at the temperature of $500^{\circ} \mathrm{C}$. There has been an increase in the size of the crystal phase clusters. The particle size is 15 to $20 \mathrm{~nm}$. Image size is $90.0 \times 90.0 \mathrm{~nm}$. 

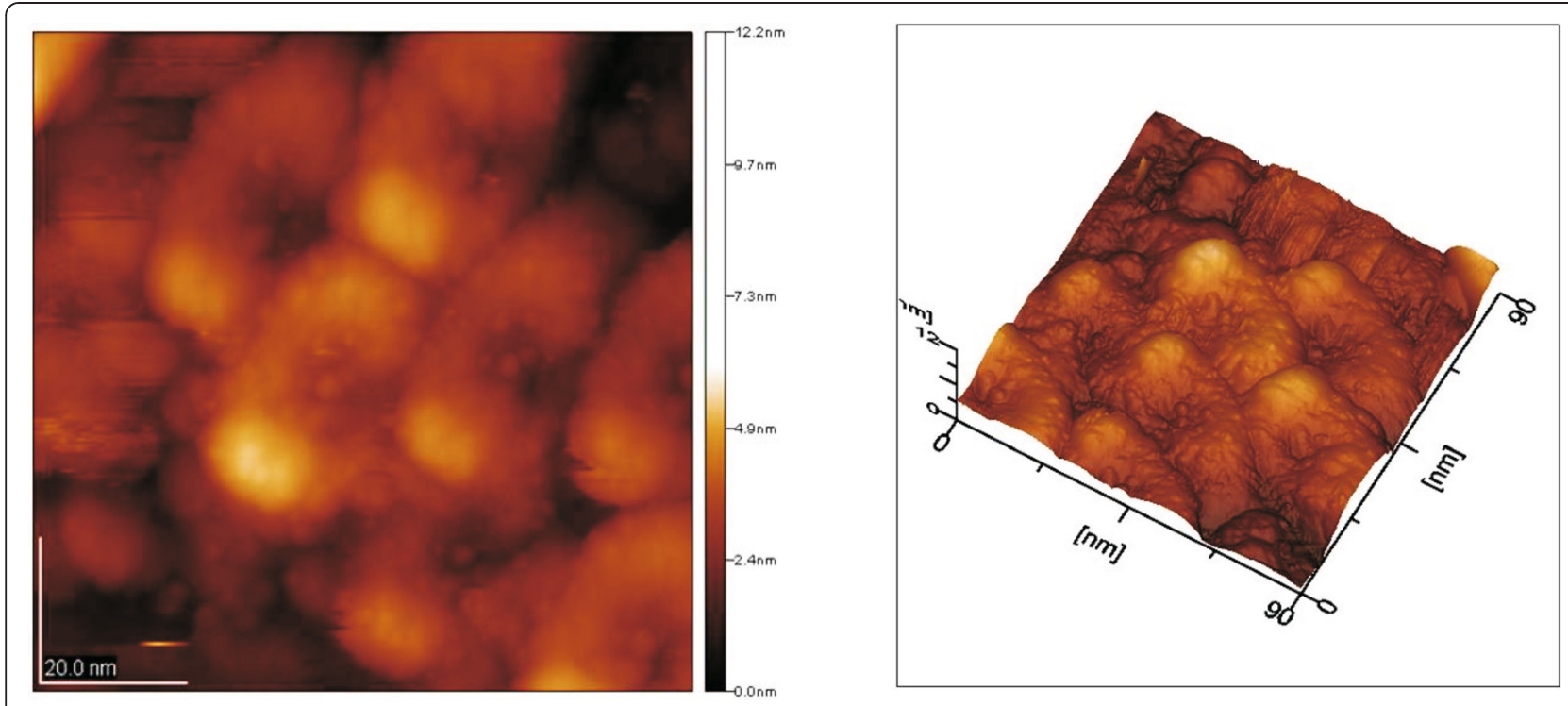

Figure $3 \mathrm{AFM}$ image of HAP samples obtained at the temperature of $700^{\circ} \mathrm{C}$. The particle size of the apatite is $40 \mathrm{~nm}$. There is a horseshoe shape of the particles. Image size is $90.0 \times 90.0 \mathrm{~nm}$; image height is $12.2 \mathrm{~nm}$.

activation of aggregation processes: coagulation and coalescence of clusters, resulting in an increase in grain size crystal phase. In Figure 2 shows a picture of nanoparticles obtained at $500^{\circ} \mathrm{C}$ temperature conditions in which the collective process of recrystallization completed.

This process continues up to a temperature of $700^{\circ} \mathrm{C}$. It should be noted that the most rapid growth of crystals occurs in the temperature range of $600^{\circ} \mathrm{C}$ to $700^{\circ} \mathrm{C}$ [1-3]. The particle size of the apatite obtained by annealing at $700^{\circ} \mathrm{C}$ is $40 \mathrm{~nm}$ (Figure 3), corresponding to a particle size of apatite in native bone. There is a horseshoe shape of the particles. However, the bone apatite particles are needle shaped. The horseshoe shape is due to the application in the synthesis of drying powder in which the ends of the particles are not committed and bent under the influence of surface tension, creating a shape that resembles a horseshoe.

Annealing at temperatures above $900^{\circ} \mathrm{C}$ leads to complex processes of mass transfer and formation of crystals

Table 1 Half width of the absorption band $v_{3}$ of studied compounds

\begin{tabular}{|c|c|}
\hline $\begin{array}{l}\text { Temperature of the HAP } \\
\text { samples annealing, } T^{\circ}{ }^{\circ} \mathrm{C}\end{array}$ & $\begin{array}{l}\text { Half width of the absorption } \\
\text { band at } 1,040 \mathrm{~cm}^{-1} \text {, } \\
\text { characterizing } \mathrm{PO}_{4}{ }^{3-} \\
\text { tetrahedra }\end{array}$ \\
\hline 200 & 130 \\
\hline 500 & 116 \\
\hline 700 & 120 \\
\hline 900 & 193 \\
\hline 1,000 & $>272$ \\
\hline
\end{tabular}

of different morphology and particle size range from 200 to $500 \mathrm{~nm}$.

The crystallization process takes place before the full absorption of the crystalline phase of amorphous matrix. Structural changes in the crystal lattice during the transition amorphous condensate-crystal phase can mostly be traced back to change the width of the vibrational bands in the spectra of crystalline lattice.

\section{IR and NMR spectroscopy of nanodispersed apatites}

It is known [1] that spectrum of initial phosphate hydroxyapatite is characterized by two intense groups of bands around 1,040 and $570 \mathrm{~cm}^{-1}$. Nine possible variations of $\mathrm{XO}_{4}$ group in the case of equivalence of all $\mathrm{X}-\mathrm{O}$ bonds, i.e., tetrahedral symmetry $T_{\mathrm{d}}$, give only two bands of IR spectrum: one band of $v_{3}$ vibrations and another of $v_{4}$ ones, the vibrations $v_{2}$ and $v_{1}$ being active only in Raman spectra [9].

If only three of four bonds are equal (symmetry $C_{3 \mathrm{v}}$ ), then total symmetric vibration $v_{1}$ becomes active, and the splitting of three degenerate vibrations $v_{3}$ and $v_{4}$ is removed partially. When there is a non-equivalence of the two X-O bonds with respect to the other two (point symmetry $C_{2 \mathrm{v}}$ ) degenerations of vibrations, $v_{3}$ and $v_{4}$ are removed completely. Finally, in the case when all four bonds are different (symmetry $C_{\mathrm{s}}$ ), there is another change in the spectrum - the removal of doubly degenerated vibration $v_{2}[9,10]$. Thus, widening the bands that correspond to vibrations of the $\mathrm{PO}_{4}$ groups indicates a decreasing of surrounding symmetry of the $\left(\mathrm{PO}_{4}\right)^{3-}$ anion in apatite sublattice. 


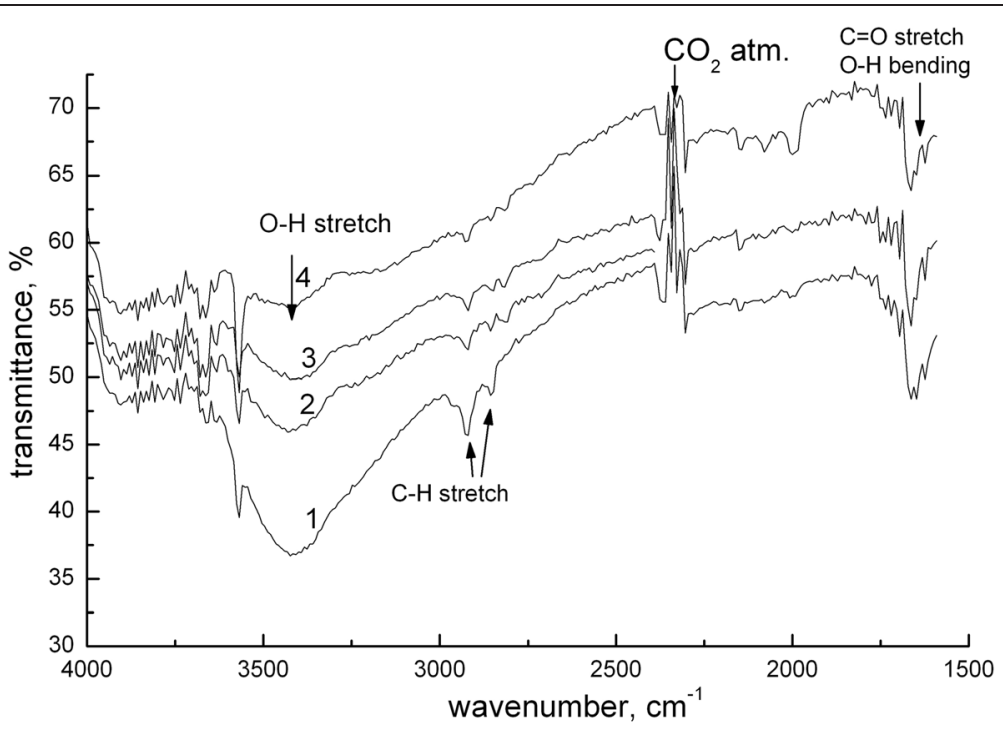

Figure 4 The presence of organic impurities in the samples according to IR spectroscopy. Annealing temperature samples: $1-200^{\circ} \mathrm{C} ; 2$ $500^{\circ} \mathrm{C} ; 3-900^{\circ} \mathrm{C} ; 4-1,000^{\circ} \mathrm{C}$. Transmission spectra were recorded in the absorption range in the 4,000 to $400 \mathrm{~cm}^{-1}$.

Study on IR spectra of samples (Table 1) revealed a lower bandwidth, characterizing $\mathrm{PO}_{4}{ }^{3-}$ tetrahedra for nanodispersed samples one to three, indicating a higher local symmetry of the $\mathrm{PO}_{4}{ }^{3-}$ tetrahedra in nanodispersed apatite in comparison with macrosamples four to five.

It should be noted that the presence of impurity atoms and other defects significantly affects vibrational infrared spectra. In the investigated samples are the presence of $\mathrm{CO}_{2}$ from the atmosphere and a small amount of residual organic reaction (Figure 4). Thermal annealing of HAP leads to changes in the hydroxyl sublattice: the number of $\mathrm{OH}^{-}$ion decreases with increasing annealing temperature, as evidenced by the decrease in the intensity of the bands at approximately 3,400 and $2,900 \mathrm{~cm}^{-1}$, which correspond to vibration stretching of $\mathrm{O}-\mathrm{H}$ and $\mathrm{C}-\mathrm{H}$ bonds (Figure 4).

To determine the effects of annealing modes on HAP samples has been used in NMR method (Figure 5). It is known that ${ }^{31} \mathrm{P}$-NMR line quite narrows for the reference

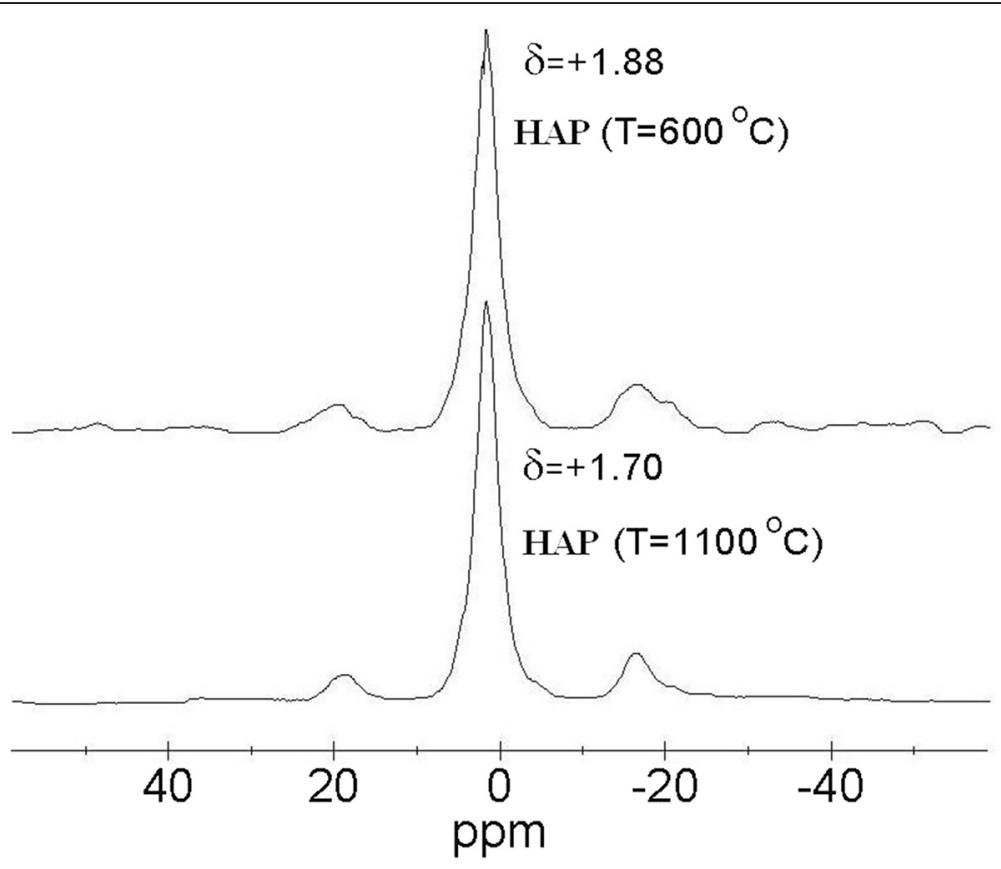

Figure $5^{31} \mathrm{P}-\mathrm{NMR}$ spectra of compounds. 
compound (phosphoric acid), whereas in the HAP, its intensity decreases, increases its half width, and maximum shifted to higher frequencies (approximately $850 \mathrm{~Hz}$ ).

${ }^{31} \mathrm{P}-\mathrm{NMR}$ spectra at annealing temperature increase are offset of the dominant signal in the direction of a strong field of $\delta=1.88$ to $\delta=1.70 \mathrm{ppm}$ (Figure 5). A significant offset of the ${ }^{31} \mathrm{P}$ spectrum to lower frequency range (Figure 5) with annealing temperature increases points to an increase in magnetic shielding of the phosphorus nuclei, which in this case means an increase in electron density on the phosphorus atoms.

\section{Conclusions}

This is a study of crystal growth mechanism of calcium hydroxyapatite in the synthesis of sol-gel method with variation of temperature parameters of synthesis within $200^{\circ} \mathrm{C}$ to $1,100^{\circ} \mathrm{C}$. The origin of crystal phase occurs in the amorphous matrix by clustering, growth, and subsequent coagulation grains with the formation of crystals in a wide range of dispersion.

Temperature determines the kinetics of structural transformation of amorphous phase in the crystal phase, which in turn affects the characteristics of the particle substructure. It is shown that the particle size of the apatite obtained that annealed $700^{\circ} \mathrm{C}$ is $40 \mathrm{~nm}$ corresponding to the particle size of apatite in native bone.

The effect of dimension factor on structural parameters of calcium hydroxyapatite is manifested in a more local symmetry of the $\mathrm{PO}_{4}^{3-}$ tetrahedra at nanosized calcium hydroxyapatite. Thermal annealing of HAP leads to changes in the hydroxyl sublattice: of number $\mathrm{OH}^{-}$ions decreases with increasing annealing temperature. A significant offset of the ${ }^{31} \mathrm{P}$ spectrum to a low frequency range with increasing annealing temperature indicates an increase of electron density on the phosphorus atoms.

\section{Competing interests}

The authors declare that they have no competing interests.

\section{Authors' contributions}

$\mathrm{KN}$ and KasV conceived and carried out the experiments, analyzed the data, and wrote the paper. KV designed the study, analyzed the data, and wrote the paper. All authors read and approved the final manuscript.

\section{Acknowledgements}

The authors gratefully acknowledge the financial support from the National Academy of Sciences of Ukraine, Ukraine (contract no. 5.16.1.25).

\section{Author details}

${ }^{1}$ G.V. Kurdymov Institute for Metal Physics of the NAS of Ukraine, blvd. Vernadsky, 36, Kiev 03680, Ukraine. Vinnytsia National Technical University, 95 Khmelnytske shose, Vinnytsia 21021, Ukraine.

Received: 20 October 2014 Accepted: 20 January 2015

Published online: 05 February 2015

\section{References}

1. Karbivskyy VL, Shpak AP. Apatite and apatite compounds. Electronic structure and properties. Kyiv: Naukova Dumka; 2010.
2. Dorozhkin SV. Nanodimensional and nanocrystalline apatites and other calcium orthophosphates in biomedical engineering, biology and medicine. Materials. 2009;4:1975-2045.

3. Dorozhkin SV. Nanosized and nanocrystalline calcium orthophosphates. Acta Biomaterialia. 2010;3:715-49.

4. Olszta MJ. Bone structure and formation: a new perspective. Mater Sci Eng. 2007:58:77-116.

5. Abidi SSA, Murtaza Q. Synthesis and characterization of nanohydroxyapatite powder using wet chemical precipitation reaction. UPB Sci Bull B. 2013;75:3-12.

6. Monmaturapoj N. Nano-size hydroxyapatite powders preparation by wet-chemical precipitation route. J Met Mater Miner. 2008;18:15-20.

7. Jothinathan E, Vanmeensel K, Vleugels J. Synthesis of nano-crystalline apatite type electrolyte powders for solid oxide fuel cells. J Eur Ceram Soc. 2010;30:1699-706.

8. Cunniffe GM, O'Brien FJ, Partap S, Levingstone TJ, Stanton KT, Dickson GR. The synthesis and characterization of nanophase hydroxyapatite using a novel dispersant-aided precipitation method. J Biomed Mater Res A. 2010;95:1142-9.

9. Nakamoto K. Infrared spectra of inorganic and coordination compounds. New Jersey: John Wiley \& Sons; 1965.

10. Cheng ZH, Yasukawa A, Kandori K, Ishikawa T. FTIR study of adsorption of $\mathrm{CO}_{2}$ on nonstoichiometric calcium hydroxyapatite. Langmuir. 1998;14:6681-6.

\section{Submit your manuscript to a SpringerOpen ${ }^{\circ}$ journal and benefit from:}

- Convenient online submission

Rigorous peer review

- Immediate publication on acceptance

- Open access: articles freely available online

- High visibility within the field

- Retaining the copyright to your article

Submit your next manuscript at springeropen.com 